\title{
Alcohol Culture, Family Structure and Adolescent Alcohol Use: Multilevel Modeling of Frequency of Heavy Drinking among 15-16 Year Old Students in 11 European Countries*
}

\author{
THORODDUR BJARNASON, PH.D., ${ }^{\dagger}$ BARBRO ANDERSSON, B.SC., ${ }^{\prime}$ MARIE CHOQUET, PH.D., ${ }^{\dagger}$ \\ ZSUZSANNA ELEKES, PH.D., ${ }^{\dagger}$ MARK MORGAN, PH.D., ${ }^{\dagger}$ AND GERTRUDE RAPINETT, M.A. ${ }^{\dagger}$ \\ Department of Sociology, University at Albany, State University of New York, Albany, New York, d the Centre for Social \\ Research and Analysis, Reykjavik, Iceland
}

\begin{abstract}
Objective: Frequency of heavy alcohol use among adolescents is examined by family structure and propensity toward heavy alcohol use on the individual level, and by alcohol availability and drinking patterns among adolescents on the societal level. The analysis includes direet effects and moderating effects of societal-level indicators on individual-level associations between family structure and frequency of heavy alcohol use. Method: The study drew upon self-reports from 34,001 students in Cyprus, France, Hungary, Iceland, Ireland, Lithuania, Malta, the Slovak Republic, Slovenia, Sweden and the United Kingdom participating in the 1999 European School Survey Project on Alcohol and Other Drugs study. Distinctions were drawn between adolescents living with both parents, a single mother, a single father, a mother and stepfather, a father and stepmother, and neither biological parent. The
\end{abstract}

multilevel analysis estimated the effects of societal-fevel factors on the intercepts and slopes of individual-level regression models. Results: Adolescents living with both biological parents engaged less frequently in heavy alcohol use than those living in any other arrangements. Ljying with a single mother was associated with less heavy drinking than living with a single father or with neither biological parent. National beer sales figures and societal patterns of heavy adoleseent alcohol use predicted more frequent heavy drinking and greater effects of living in nonintact farmilies. Conclusions: Adolescent heavy drinking is more common in all types of nonintact families. The adverse effect of living in nonintact families is greater in societies where alcohol availability is greater and where adolescents drink more heavily. (J. Stud. Alcohol 64: 200-208, 2003)
$\mathrm{H}$ EAVY ALCOHOL USE constitutes a major problem for the physical, psychological and social well-being of adolescents. It involves serious short-term and long-term health risks (Hansell et al., 1999; Lieber, 1998) and anticipates future problem drinking (Hawkins et al., 1997; Pedersen and Skrondal, 1998) and illicit drug use (Kandel and Yamaguchi, 1993; Pacula, 1998). Such use is also associated with a host of other negative behavioral consequences, including accidents (Dufour, 1996), violent behavior and victimization (Bernburg and Thorlindsson, 1999; Ullman et al., 1999) and suicidal behavior (Bjarnason and Thorlindsson, 1994; Rossow and Wichstrøm, 1994), as well as early sexual debut and unprotected sex (Miller et al., 1995; Poulin and Graham, 2001). Furthermore, frequent

Received: May 1, 2002. Revision: September 13, 2002.

*This project was facilitated by a grant from the Scandinavian Research Council for Criminology.

tCorrespondence should be sent to Thoroddur Bjarnason, Department of Sociology, Univerisity at Albany, State University of New York, Albany, NY 12222, or via email to: thor@albany.edu. Barbro Andersson is with the Swelish Council for Information on Alcohol and Other Drugs, Stockholm, Sweden. Marie Choquet is with the Institut National de la Santé et de la Recherche Médicale, Villejuif Cedex, France. Zsuzsanna Elekes is with the Department of Sociology, Budapest University of Economic Sciences, Budapest, Hungary. Mark Morgan is witlı St. Patrick's College, Dublin, Ireland. Gertrude Rapinett is with the University of Malta, Msida, Malta. and heavy adolescent alcohol use is associated with personal problems with family, friends, employers, school authorities and the police (Hemmingsson et al., 1999; Pedersen, 1996).

Although the propensity for problem drinking may in part be rooted in biological and genetic factors (e.g., Koopmans and Boomsma, 1996), such behavioral patterns develop in a multilevel social context, ranging from interpersonal relationships to societal-level structural constraints and cultural traditions. In this article, we examine the interaction of societal-level alcohol culture and individual family context on the frequency of adolescent heavy drinking. Specifically, we model the direct effects of adult and adolescent drinking cultures on the frequency of heavy drinking and the moderating effects of such societal-level consumption patterns on the individual-level associations between family structure and heavy drinking among 15-16 year old students in 11 European countrics. This enables us to examine the relative impact of societal alcohol availability and societal patterns of adoleseent alcohol use, and the role of family structure at the intersection of adult and adolescent societies.

\section{Heavy alcohol une across adult and achlesent sociedies}

Differences in patterns of alcohol eonsumption between countries are a continuous subject of scientiffe inquiry as 
well as popular folklore. For instance, Mediterranean alcohol cultures have been widely characterized by moderate daily consumption of wine, whereas the Nordic countries have been noted for sporadic bouts of heavy spirit consumption (see, e.g., Room and Mäkelä, 2000). Such images have given rise to a variety of overlapping systems of classification, such as the distinctions between "proscriptive," "prescriptive" and "permissive" alcohol cultures; "dry" and "wet" alcohol cultures; cultures traditionally dominated by the consumption of beer, wine or spirits; and, more recently, cultural patterns of "abstinence," "ritual consumption," "banalized consumption" or "fiesta consumption" (Room and Mäkelä, 2000).

Cross-cultural studies have found such distinctions between different alcohol cultures useful in explaining national differences in a variety of alcohol-related social problems, including, for example, patterns of mortality rates (Peele, 1997), psychological and physiological dependence symptoms (Schmidt et al., 1999) and differences in the association between alcohol consumption and homicide (Rossow, 2001). Such studies have, however, not examined the relative impact of adult and adolescent alcohol cultures on individual patterns of heavy drinking. This can in part be traced to the lack of adequate comparative data. Studies conducted in a single country can provide some insight into the relationship between adult and adolescent drinking cultures (see, e.g., Dean, 1990; Wada et al., 1998), but such studies lack the comparison level needed to specify the relationship between adult and adolescent drinking patterns in a cross-cultural perspective.

The culture generated within adolescent society intersects with mainstream society at several points, but it is in part formed in distinction or even in opposition to the norms and expectations of adult societies (Bjarnason, 2000; Coleman, 1961). Adult society constantly attempts to inpose behavioral rules on adolescents that may be radically different from the norms to which adults are expected to adhere (Thorlindsson et al., 2001). From the perspective of adolescents, alcohol use may represent a desire for early transition into adult social roles by adopting "adult" behavioral patterns. However, alcohol use also may constitute a form of rebellion against parental control, and the normative consensus among parents against such behavior may be counterproductive in instigating more frequent and heavy alcohol use among adolescents. Furthermore, alcohol is an integral part of the pursuit of excitement and fun that characterizes adolescent society (Jensen and Brownfield, 1986), and more frequent heavy alcohol use may simply be a reflection of the dynamics of adolescent society.

In societies where alcohol is more prevalent, adolescents may have more opportunities to engage in heavy drinking. However, countries with a tradition of high per capita alcohol consumption may nevertheless successfully socialize adolescents into responsible drinking practices, or they may successfully impose nomative constraints against adolescent alcohol use. Conversely, countries where per capita alcohol consumption is relatively low may nevertheless fail to promote responsible drinking among adolescents and may have relatively less control over adolescent behaviors. Adolescent drinking culture may thus to some extent vary independently of the drinking culture of wider society.

\section{The role of family structure in adolescent alcohol use}

Prior research has consistently found that adolescents who do not live with both biological parents drink alcohol more frequently and more heavily (e.g., Bergmark and Andersson, 1999; Foxcroft and Lowe, 1991; Miller, 1997). However, such studies have in most instances been unable to distinguish between different types of nonintact families, in part because the vast majority of adolescents in such households live with either their mother or their mother and stepfather.

The relative rarity of adolescents living with a single father, father and stepmother or neither biological parent has precluded rigorous analysis of the relative impact of each type of nonintact families. This has forced researchers either to discard the less common nonintact family types or to collapse them into broader categories, such as, for example, "nonintact families," "single-parent families" or "parent-stepparent families." Studies focusing on the difference between such broad categories have yielded somewhat inconsistent results. Thus, some scholars have found adolescent alcohol consumption in single-parent families to be similar to that in stepfamilies (e.g., Adlaf and Ivis, 1996; Forgays, 1998; Glendinning et al., 1997). Others have found it to be more similar to that in families with two biological parents present (e.g., Adalbjarnardottir et al., 1997; Amey and Albrecht, 1998).

The effects of family structure on adolescent alcohol use appear to operate primarily through deteriorated relations between adolescents and their parents. Thus, once different measures of the quality of parental relations are taken into account, the association between family structure and adolescent alcohol use has been found to be substantially reduced (Ely et al., 2000; Shucksmith et al., 1997) or even eliminated (Sokol-Katz et al., 1997; Wallace et al,, 1999). Furthermore, the adverse effect of living with a single mother appears to depend in part on the involvement of the nonresident father (Thomas et al., 1996). The effect of family structure on adolescent alcohol use should, however, not be considered spurious, but should rather be interpreted as a proxy for various emotional and social family processes that result in decreased parental involvement in the lives of adolescents. The hypothesized effects of alcohol culture on the association between family structure and frequent adolescent heavy drinking may, therefore, be indicative of more general moderating effects of alcohol culture on the effect of interpersonal family relations. 
We expect both adult and adolescent drinking cultures to affect the association between family structure and adolescent heavy drinking. The deficiencies apparently associated with nonintact households are expected to be more consequential when alcohol is more readily available in society at large and when alcohol consumption is more prevalent in adolescent society. In other words, adolescents who do not live with both parents may have greater opportunities to take advantage of the availability of alcohol in society at large, and they may become more involved in the adolescent drinking culture. Such involvement can take the form of both more frequent occasions of heavy drinking and heavier drinking on such occasions. In this study we focused specifically on predictors of frequency rather than quantity of heavy drinking, and thus we controlled for the number of drinks per drinking occasion.

\section{Method}

\section{Data}

The data used in this study were drawn from the 1999 European School Survey Project on Alcohol and Other Drugs (ESPAD; Hibell et al., 2000). The 11 countries from which data were available for the current study (Cyprus, France, Hungary, Iceland, Ireland, Lithuania, Malta, the Slovak Republic, Slovenia, Sweden and the United Kingdom) provided a generally balanced geographical selection of countries. Table 1 shows that these 11 countries have a prevalence rate of 30-day heavy drinking that is almost identical to that of the other 17 ESPAD countries that employed this measure.

Depending on geographical characteristics, population size and other logistic considerations, the samples in each country were drawn as either random samples of all classes in each country, geographically stratified random samples of classes or two-stage random samples of schools and classes (Hibell et al., 2000). The school class was the final sampling unit in all countries. Anonymous questionnaires were administered to all students born in 1983 who were present in class on the day of survey administration in March-May 1999 (January 1999 in Malta). The respondents were thus 15-16 years old at the time of the survey, with the country-specific mean age varying from 15.1 to 15.3 years.

The surveys were administered in individual countries by research assistants, teachers or other school employees, and students sealed them in blank envelopes upon completion. A methodological study of such differences in administration mode found no systematic difference in response rates or self-reported substance use (Bjarnason, 1995). Response rates in the 11 countries varied between $86 \%$ and $92 \%$, with the exception of Malta $(77 \%)$. Despite an earlier date of administration and lower response rate, the Maltese
TABLE 1. Percentages of 15-16 year old European students who report drinking five drinks or more on a single occasion during the past 30 days

\begin{tabular}{lccc}
\hline Countries & All students & Males & Females \\
\hline Bulgaria & 33 & 43 & 25 \\
Croatia & 31 & 38 & 24 \\
Cyprus (Greek) & $\mathbf{3 8}$ & $\mathbf{5 1}$ & $\mathbf{2 7}$ \\
Czech Republic & 43 & 54 & 34 \\
Denmark & 64 & 72 & 56 \\
Estonia & 47 & 55 & 41 \\
Faroe Islands & 34 & 40 & 29 \\
Finland & 48 & 53 & 43 \\
France & $\mathbf{3 3}$ & $\mathbf{4 0}$ & $\mathbf{2 5}$ \\
FYROM & 28 & 38 & 19 \\
Greece & 31 & 41 & 24 \\
Greenland & 59 & 60 & 59 \\
Hungary & $\mathbf{2 3}$ & $\mathbf{2 9}$ & $\mathbf{1 8}$ \\
Iceland & $\mathbf{2 8}$ & $\mathbf{3 1}$ & $\mathbf{2 6}$ \\
Ireland & $\mathbf{5 7}$ & $\mathbf{5 7}$ & $\mathbf{5 6}$ \\
Latvia & $\mathbf{4 5}$ & 51 & 40 \\
Lithuania & $\mathbf{3 6}$ & $\mathbf{4 7}$ & $\mathbf{2 6}$ \\
Malta & $\mathbf{4 8}$ & $\mathbf{5 6}$ & $\mathbf{4 2}$ \\
Norway & 50 & 50 & 51 \\
Poland & 46 & 56 & 37 \\
Portugal & 23 & 29 & 18 \\
Ronnania & 27 & 38 & 19 \\
Russia (Moscow) & 40 & 46 & 35 \\
Slovak Republic & $\mathbf{3 1}$ & $\mathbf{3 8}$ & $\mathbf{2 5}$ \\
Slovenia & $\mathbf{4 7}$ & $\mathbf{5 1}$ & $\mathbf{4 2}$ \\
Sweden & $\mathbf{4 3}$ & $\mathbf{4 7}$ & $\mathbf{3 8}$ \\
Ukraine & $\mathbf{3 5}$ & 41 & 29 \\
United Kingdom & $\mathbf{5 6}$ & $\mathbf{5 7}$ & $\mathbf{5 5}$ \\
Average of 28 & & & \\
$\quad$ European countries & 40 & 47 & 34 \\
Average of 11 & $\mathbf{4 0}$ & $\mathbf{4 6}$ & $\mathbf{3 5}$ \\
$\quad$ European countries & & & \\
\hline
\end{tabular}

Source: The 1999 European School Survey Project on Alcohol and Other Drugs; Hibell et al., 2000.

Note: Eleven countries included in the present study are boldface. "Former Yugoslav Republic of Macedonia.

data are considered comparable to the data from the other countries (Hibell et al, 2000).

For the purposes of the current study, responses from 218 students $(0.6 \%)$ with missing values on the dependent variable were omitted from further analysis, leading to a net sample of 34,001 students. The national samples ranged from 2,275 students in France to 5,039 students in Lithuania. Weights were applied to the final data to correct for sampling design and unequal sample sizes, with equal weights assigned to each of the 11 countries in the full dataset. This procedure prevents countries with larger sample sizes from disproportionately affecting the estimation of the statistical models.

\section{Measures of drinking culture}

Country-level information on adoleseent drinking patterns were available for all 11 countries; information on national alcohol sales was available for 9 countries. Our models of adolescent drinking culture were thus based on the sample of 11 countries, and our models simultaneously 
estimating adolescent and adult drinking culture were based on a 9-country subsample. Table 2 shows descriptive sta-. tistics for the variables in each of these two samples.

National sales figures for beer, wine and distilled spirits in 1999 were obtained from World Drink Trends 2000 (NTC, 2000) and were recalculated as liters of pure alcohol. As a proxy measure of adult drinking culture, these figures are subject to an unknown level of measurement error and should be interpreted with caution. We tested the effectiveness of these alternative measures, and we found that the sales figures for wine and spirits had trivial, inconsistent and in almost all cases nonsignificant effects on the frequency of heavy adolescent alcohol use. We did find weak, albeit inconsistent, effects of total alcohol sales, but these effects could be attributed entirely to the beer component of this measure. Here we report findings based only on sales figures for beer, but other results are available from the first author upon request.

Individual patterns of alcohol consumption were measured by the number of drinks of beer, wine and spirits consumed on the last drinking occasion. In the standard ESPAD questionnaire, "a drink" was defined as $50 \mathrm{cl}$ beer, $10 \mathrm{cl}$ wine or $5 \mathrm{cl}$ spirits. These amounts were redefined in culturally relevant terms in each country. For each beverage, the responses ranged from 0 ("never drink" or "didn't drink that beverage on last occasion") to 5 ("five drinks or more"). Our measure of adolescent drinking culture was obtained by averaging the number of alcoholic drinks students in each country reported drinking on their last drinking occasion.

\section{Family structure}

Responses to a checklist of individuals living in the household with the respondent were used to construct six binary variables indicating family structure: (1) mother and father, (2) mother and stepfather, (3) father and stepmother, (4) mother only, (5) father only and (6) other arrangements. The final category (6) included students who lived alone or only with stepparent(s) or foster parent(s), grandparent(s),

TABLE 2. Descriptive statistics for multilevel analysis of heavy drinking in past 30 days among $15-16$ year old European students

\begin{tabular}{|c|c|c|c|c|c|c|c|}
\hline & \multirow[b]{2}{*}{ Range } & \multicolumn{3}{|c|}{ Eleven countries ${ }^{a}$} & \multicolumn{3}{|c|}{ Nine countries ${ }^{b}$} \\
\hline & & Mean & $\mathrm{SE}$ & $\mathrm{SD}$ & Mean & $\mathrm{SE}$ & SD \\
\hline \multicolumn{8}{|l|}{$\begin{array}{l}\text { Country level } \\
\text { Alcohol sales } \\
\text { (liters alcohol) }\end{array}$} \\
\hline Beer & $1.9-7.7$ & - & - & - & 3.59 & .62 & 1.86 \\
\hline Wine & $0.8-6.9$ & - & - & - & 2.57 & .62 & 1.85 \\
\hline Spirits & $1.0-4.2$ & - & - & - & 2.11 & .35 & 1.05 \\
\hline Total & $4.0-11.3$ & - & - & - & 7.70 & .88 & 2.65 \\
\hline \multicolumn{8}{|l|}{ Adolescent drinking culture } \\
\hline $\begin{array}{l}\text { Country average number } \\
\text { drinks on last occasion }\end{array}$ & $1.7-3.6$ & 2.62 & .19 & 0.63 & 2.62 & .23 & 0.70 \\
\hline \multicolumn{8}{|l|}{ Family structure (\%) } \\
\hline Both biological parents & $0.67-0.93$ & 0.79 & .03 & 0.09 & 0.80 & .03 & 0.10 \\
\hline Single mother & $0.03-0.14$ & 0.10 & .01 & 0.04 & 0.09 & .01 & 0.04 \\
\hline Single father & $0.01-0.05$ & 0.02 & .003 & 0.01 & 0.02 & .004 & 0.01 \\
\hline Mother and stepfather & $0.01-0.12$ & 0.06 & .01 & 0.04 & 0.06 & .01 & 0.04 \\
\hline Father and stepmother & $0.00-0.02$ & 0.01 & .002 & 0.01 & 0.01 & .002 & 0.01 \\
\hline Other arrangements & $0.01-0.05$ & 0.02 & .003 & 0.01 & 0.02 & .003 & 0.01 \\
\hline \multicolumn{8}{|l|}{ Individual level } \\
\hline \multicolumn{8}{|l|}{ Controls } \\
\hline Female & $0-1$ & 0.50 & .003 & - & 0.51 & .003 & $\overline{1}$ \\
\hline Perceived SES & $1-7$ & 3.41 & .01 & 1.09 & 3.31 & .01 & 1.08 \\
\hline \multicolumn{8}{|l|}{ Family structure" $(\%)$} \\
\hline Both biological parents & 0.1 & 0.79 & .002 & - & 0.80 & .002 & - \\
\hline Single mother & $0-1$ & 0.10 & .002 & - & 0.09 & .002 & - \\
\hline Single father & $0-1$ & 0.02 & .001 & - & 0.02 &, 001 & - \\
\hline Mother and stepfather & $0-1$ & 0.06 & .001 & - & 0.06 & .001 & - \\
\hline Father and stepmother & $0-1$ & 0.01 & .001 & - & 0.01 & .001 & - \\
\hline Other arrangements & $0-1$ & 0.02 & .001 & - & 0.02 & .001 & - \\
\hline \multicolumn{8}{|c|}{ Number of drinks on last occasion } \\
\hline Beer & 0.5 & 0.99 & .01 & 1.55 & 1.03 & .01 & 1.61 \\
\hline Wine & $0-5$ & 0.63 & .01 & 1.15 & 0.54 & .01 & 1.07 \\
\hline Spirits & $0-5$ & 0.98 & .01 & 1.49 & 1.03 & .01 & 1.51 \\
\hline $\begin{array}{l}\text { Dependent variable } \\
\text { 30-day heavy drinking }\end{array}$ & $0-6$ & 1.08 & .01 & 1.74 & 1.12 & .01 & 1.79 \\
\hline
\end{tabular}

"Cyprus, France, Hungary, Iceland, Ireland, Lithuania, Malta, Slovak Republic, Slovenia, Sweden, United Kingdom, "Cyprus, France, Hungary, Iceland, Ireland, Malta, Slovak Republic, Sweden, United Kingdom. "Mother and father are contrast. 
sibling(s), other relative(s) or nonrelative(s). Across the 11 countries, an average of $79 \%$ of the students lived with both biological parents, $10 \%$ lived with their single mother and $6 \%$ lived with their mother and stepfather. The remaining $5 \%$ lived with a single father, with a father and stepmother or in other arrangements. The highest proportions of two biological parent families were to be found in Malta (93\%) and Cyprus (91\%), and the lowest in Iceland (67\%).

\section{Control variables}

In our analysis, we controlled for gender and perceived socioeconomic status (SES). Female respondents were coded 1 ; male respondents were coded 0 . Perceived SES was measured by responses to the question "How well off is your family compared to other families in your country?" The responses were coded from 1 ("very much worse off") to 7 ("very much better off").

\section{Dependent variable}

The dependent variable asks how often in the past 30 days the respondent had five or more drinks on a single drinking occasion. This variable was coded on a sevenpoint scale, ranging from 0 ("never") to 6 ("10 times or more").

\section{Statistical procedures}

The following analysis was based on "hierarchical" or "multilevel" modeling techniques (Bryk and Raudenbush, 1992). This method allowed us to estimate the effects of societal-level drinking culture on individual heavy drinking, after taking into account the effects of family structure, gender, parental SES and individual propensity for heavy alcohol consumption per occasion. We also were able to estimate the moderating effects of country-level measures of adult and adolescent drinking patterns on the strength of the relationship between family structure and frequency of heavy drinking. Finally, we were able to test the significance of between-country differences in individual-level coefficient in order to identify factors that differ between countries in the strength of their association with adolescent heavy drinking. This allowed us to test the hypothesis that the effects of living in arrangements other than with two biological parents would vary directly. with societal alcohol availability and societal patterns of adolescent drinking.

\section{Results}

Table 3 shows the results of the multilevel regression model of adolescent drinking culture, individual drinking patterns and family structure in the 11 countries. In Model
1, heavy drinking per occasion is excluded from the analysis. In this model, the country average number of drinks on last drinking occasion significantly predicts individual frequency of heavy drinking, net of individual-level factors. Females engage significantly less frequently in heavy drinking than males, and perceived SES of the family is likewise associated with less frequent heavy drinking. A chi-square test of the strength of these predictors reveals a significant unexplained difference in the association between gender and the frequency of heavy drinking across the 11 countries $\left(\chi^{2}=147.6,10 \mathrm{df}, p<.001\right)$, but there is no significant between-country variation in the effects of perceived SES.

Heavy drinking is more frequent among adolescents living in nonintact families than among their counterparts who live with both biological parents. As expected, heavier drinking in adolescent society increases the individual effect of living in nonintact families, with the exception of a nonsignificant effect of living with a father and stepmother. The effects of family structure on the frequency of heavy drinking are modeled as fixed effects, because they do not differ

TABLE 3. Multilevel analysis of heavy drinking in past 30 days among 15 16 year old students in 11 European countries by family structure and adolescent and adult alcohol culture (unstandardized HLM regression coefficients)

\begin{tabular}{|c|c|c|c|c|}
\hline & \multicolumn{2}{|c|}{ Model 1} & \multicolumn{2}{|c|}{ Model 2} \\
\hline & $\begin{array}{l}\text { Fixed } \\
\text { effect }\end{array}$ & Variance & $\begin{array}{l}\text { Fixed } \\
\text { effect }\end{array}$ & Variance \\
\hline \multicolumn{5}{|l|}{ Country level } \\
\hline Intercept & $1.09 \ddagger$ & $.09 \ddagger$ & $1.10^{\ddagger}$ & $.10^{\ddagger}$ \\
\hline Adolescent drinking culture & & & & \\
\hline $\begin{array}{l}\text { Country average number of } \\
\text { drinks on last occasion (CAD) }\end{array}$ & $0.70^{\ddagger}$ & & $0.43 \neq$ & \\
\hline \multicolumn{5}{|l|}{ Individual level } \\
\hline \multicolumn{5}{|l|}{ Controls } \\
\hline Female & $-0.41^{\ddagger}$ & $.05 \ddagger$ & $-0.04^{n x}$ & $.02 \ddagger$ \\
\hline Perceived SES & $-0.02^{*}$ & Fixed & $-0.03 *$ & Fixed \\
\hline \multicolumn{5}{|l|}{ Family structure ${ }^{a}$} \\
\hline Single mother & $0.23+$ & Fixed & 0.134 & Fixed \\
\hline Single mother by $\mathrm{CAD}$ & $0.20^{\ddagger}$ & & $0.16^{\mathrm{t}}$ & \\
\hline Single father & $0.41^{\ddagger}$ & Fixed & $0.21 \%$ & Fixed \\
\hline Single fither by $C A D$ & $0.28^{*}$ & & $0.20^{*}$ & \\
\hline Mother and step father & $0.35 t$ & Fixed & $0.18^{*}$ & Fixed \\
\hline Mother and stepfather by CAD & 0.23 & & $0.15 \%$ & \\
\hline Father and stepmother & $0.38 *$ & Fixed & $0.06^{\mathrm{ms}}$ & lixed \\
\hline Father and stepmother by $\mathrm{CAD}$ & $0.19^{n \cdot r}$ & & $0.16^{\mathrm{Br}}$ & \\
\hline Other arrangements & $0.50 *$ & Fixed & $0.26 *$ & Fixed \\
\hline Other arrangements by $\mathrm{CAD}$ & $0.50 \%$ & & $0.40 *$ & \\
\hline \multicolumn{5}{|l|}{ Number of drinks on last oectsion } \\
\hline Beer & & & $0.40 \%$ & Fixed \\
\hline Wine & & & 0.23 & Fixed \\
\hline Spirits & & & $0.43 *$ & Fixed \\
\hline \multicolumn{5}{|l|}{ Explained varianee } \\
\hline Country-level & 0.57 & & 0.54 & \\
\hline Individual-level & 0.03 & & 0.39 & \\
\hline
\end{tabular}

Notes: Countries: Cyprts, France, Hungary, Iceland, Ireland, Lithusuia, Malta, Slovak Republic, Slovenia, Sweden, United Kingdon. "Living with both biological parents is contrast.

${ }^{*} p<.05 ;{ }^{\dagger} p<.01 ;{ }^{\dagger} p<.001$; "nonsignificant. 
significantly between countries after the moderating effects of adolescent alcohol culture have been taken into account.

In Model 2, heavy drinking per occasion is included in the analysis. As could be expected, the frequency of heavy drinking is significantly associated with the number of drinks of beer, wine and spirits consumed on the last drinking occasion. Taking such consumption patterns into account renders the main effect of gender on heavy drinking nonsignificant, although the effect of gender on frequency of heavy drinking continues to vary significantly across countries $\left(\chi^{2}=89.7,10 \mathrm{df}, p<.001\right)$. Adolescent drinking culture continues to yield a significant effect on individual-level frequency of heavy drinking. Heavy drinking continues to be significantly higher anong those living in most types of nonintact families, and this effect is found to be stronger in societies where adolescents drink more heavily. The exception to this pattern is a nonsignificant effect of living with one's father and stepmother.

Table 4 shows the results of the multilevel regression model of both adult and adolescent drinking culture, individual drinking patterns and family structure in the nine countries for which alcohol sales figures were available. In Model 3, adolescent drinking culture and individual drinking patterns are excluded from the analysis. In this model, beer sales significantly predict individual frequency of adolescent heavy drinking, net of individual-level factors. As in the 11-country sample, females drink significantly less heavily than males, and perceived SES of the family is likewise associated with less frequent heavy drinking.

We find that in the nine-country sample heavy drinking is again more frequent among adolescents living in nonintact families. As hypothesized, per capita sales of beer are associated with an increase in frequency of heavy drinking for those living in such families, with the exception of those living with their father and stepmother.

In the final model (Table 4, Model 4), adolescent drinking culture and individual drinking patterns are added to the analysis. As in the 11-country sample, the frequency of heavy drinking is significantly predicted by the number of drinks consumed on the last drinking occasion. After individual-level effects have been taken into account, both the adult drinking culture and the adolescent drinking culture continue to yield a significant effect on individual-level frequency of heavy drinking. As in Model 3, heavy drinking continues to be significantly higher among those living in nonintact families, with the exception of those living with their father and stepmother. The effects of living with a single mother or with neither biological parent are stronger where beer sales are higher and where adolescents drink more per occasion. For those living with a single father, a statistically significant moderating effect is found for adolescent drinking culture only, and for those living with a mother and stepfather a moderating effect is found only for beer sales.
TABLE 4. Multilevel analysis of heavy drinking in past 30 days among 15 16 year old students in nine European countries by family structure, and adolescent and adult alcohol culture (unstandardized HLM regression coefficients)

\begin{tabular}{|c|c|c|c|c|}
\hline & \multicolumn{2}{|c|}{ Model 3} & \multicolumn{2}{|c|}{ Model 4} \\
\hline & $\begin{array}{l}\text { Fixed } \\
\text { effect }\end{array}$ & Variance & $\begin{array}{l}\text { Fixed } \\
\text { effect }\end{array}$ & Variance \\
\hline \multicolumn{5}{|l|}{ Country level } \\
\hline Intercept & $1.13^{\ddagger}$ & .18 & $1.14 t^{\ddagger}$ & $.08^{\ddagger}$ \\
\hline \multicolumn{5}{|l|}{ Alcohol sales } \\
\hline Beer sales (BS) & $0.20^{\dagger}$ & & $0.09^{*}$ & \\
\hline \multicolumn{5}{|l|}{ Adolescent drinking culture } \\
\hline \multicolumn{4}{|l|}{ Country average number of } & \\
\hline \multicolumn{5}{|l|}{ Individual level } \\
\hline \multicolumn{5}{|l|}{ Controls } \\
\hline Female & $-0.40^{\ddagger}$ & $.06^{\ddagger}$ & $-0.03^{n s}$ & $.02 \ddagger$ \\
\hline Perceived SES & $-0.02 *$ & Fixed & $-0.03 \ddagger$ & Fixed \\
\hline \multicolumn{5}{|l|}{ Family structure ${ }^{a}$} \\
\hline Single mother & $0.26^{\ddagger}$ & Fixed & $0.16^{\ddagger}$ & Fixed \\
\hline Single nother by BS & $0,06^{\dagger}$ & & $0.05^{\dagger}$ & \\
\hline Single mother by CAD & & & $0.09^{*}$ & \\
\hline Single father & $0.47 \ddagger$ & Fixed & $0.22 \ddagger$ & Fixed \\
\hline Single father by BS & $0.14^{\dagger}$ & & $0.03^{M S}$ & \\
\hline Single father by CAD & & & $0.20^{*}$ & \\
\hline Mother and stepfather & $0.37 \ddagger$ & Fixed & $0.21 \ddagger$ & Fixed \\
\hline Mother and stepfather by BS & $0.08^{*}$ & & $0.06^{*}$ & \\
\hline Mother and stepfather by CAD & & & $0.10^{n s}$ & \\
\hline Father and stepmother & $0.42 \ddagger$ & Fixed & $0.09^{\text {m.s }}$ & Fixed \\
\hline Father and stepmother by BS & $0.05^{n s}$ & & $0.01 \mathrm{~ms}$ & \\
\hline Father and stepmother by CAD & & & $0.16^{n s}$ & \\
\hline Other arrangements & $0.69 \ddagger$ & Fixed & $0.35^{\ddagger}$ & Fixed \\
\hline Other arrangements by BS & $0.20 \ddagger$ & & $0.07^{*}$ & \\
\hline Other arrangements by $\mathrm{CAD}$ & & & $0.35 \ddagger$ & \\
\hline \multicolumn{5}{|l|}{ Number of drinks on last occasion } \\
\hline Beer & & & $0.40 \ddagger$ & Fixed \\
\hline Wine & & & $0.22 \ddagger$ & Fixed \\
\hline Spirits & & & $0.45^{\ddagger}$ & Fixed \\
\hline \multicolumn{5}{|l|}{ Explained variance } \\
\hline Country-level & 0.30 & & 0.69 & \\
\hline Individual-level & 0.03 & & 0.39 & \\
\hline
\end{tabular}

Notes: Countries: Cyprus, France, Hungary, Iceland, Ireland, Malta, Slovak

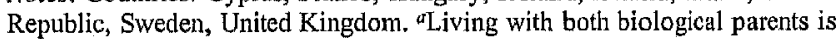
contrast,

${ }^{*} p<.05 ;{ }_{p}<.01 ; \ddagger_{p}<.001 ;{ }^{n}$ nonsignificant.

A comparison of the relative effects of different nonintact family structures shows that adolescents living with a single mother are generally somewhat better off than their counterparts in other nonintact households. Controlling for the moderating effects of adolescent drinking culture (Model $1)$, adolescents living with a single mother are less disadvantaged $(\beta[\mathrm{SE}]=0.23[0.03])$ than those living with a single father $\left(\beta=0.41[0.07] ; \beta_{\Delta}\right.$ (difference in $\left.\beta\right)=0.18$ $[0.15] ; \mathrm{CI}=95 \%)$, with a mother and stepfather $(\beta=0.35$ $[0.04] ; \beta_{\Delta}=0.12[0.10]$ or in other arrangements $(\beta=0.50$ $\left.[0.06] ; \beta_{\Delta}=0.27[0.13]\right)$. Similarly, when the moderating effects of national beer sales are controlled for (Model 3), adolescents living with a single mother are less disadvantaged $(\beta=0.26[0.03])$ than those living with a single father 
$\left(\beta=0.47[0.07] ; \beta_{\Delta}=0.21[0.15]\right)$, with a mother and stepfather $\left(\beta=0.37[0.04] ; \beta_{\Delta}=0.11[0.10]\right)$ or in other arrangements $\left(\beta=0.69[0.06] ; \beta_{\Delta}=0.43\right.$ [0.13]). The difference between adolescents living with a single mother and those living with a father and stepmother (Model 1: $\beta$ $=0.38$ [0.09]; Model 3: $\beta=0.42[0.09]$ ) is in the same direction, but it does not reach statistical significance (Model 1: $\beta_{\Delta}=0.15$ [0.19]; Model 3: $\beta_{\Delta}=0.16[0.19]$ ).

This relatively smaller disadvantage of living with a single mother compared with other nonintact family structures involving at least one biological parent appears to be related to heavy drinking in general rather than specifically the frequency of such drinking. Once the quantity of alcohol consumed at last drinking occasion is controlled for (Models 2 and 4), adolescents living with a single mother are only relatively less disadvantaged than those living in other arrangements (Model 2: $\beta_{\Delta}=0.13$ [0.11]; Model 4: $\beta_{\Delta}=0.19$ [0.13]).

The final model reduces the unexplained variance in the frequency of heavy drinking between countries by $69 \%$, and the unexplained variance in the frequency of heavy drinking between individuals by $39 \%$. It should, however, be noted that our control for individual propensity toward heavy drinking contributes substantially to the fit of the final model. Furthermore, the variation in the intercepts between countries remains statistically significant $\left(\chi^{2}=\right.$ $1,012.2,6 \mathrm{df}, p<.001$ ). In other words, there remain significant country level differences in the frequency of heavy drinking that cannot be explained by the estimated model.

\section{Discussion}

In this study we analyzed the frequency of heavy drinking among adolescents living in a wide variety of economic, political and cultural settings, ranging from traditional Western European bastions of industrial capitalism and liberal democracy to Eastern European countries that gained political independence and abandoned state-run political economies during the childhood of our adolescent respondents. These countries represent the entire range of European alcohol cultures, including traditional Southern European wine cultures, Central European beer cultures and Northern European spirit cultures.

In each of these countries we found that adolescents engaged more frequently in heavy drinking when they did not live with both biological parents. Adolescents living with both biological parents drink less heavily than those living in any other arrangements, and adolescents living with a single mother drink less heavily than those who live with a single father or with neither parent. These findings add to a large body of research that has found adolescents who reside with both biological parents to be less likely to drink alcohol than those living in other arrangements (e.g., Bergmark and Andersson, 1999; Foxcroft and Lowe, 1991;
Miller, 1997). They also lend support to those studies that have found that the presence of a stepparent does not counteract the adverse effect of living with only one biological parent (Adlaf and Ivis, 1996; Forgays, 1998; Glendinning et al., 1997). Our findings further suggest that, despite continuing concerns over the effects of single motherhood on the well-being of adolescents, other types of nonintact families may be more strongly associated with the frequency of heavy alcohol consumption.

In most cases the detrimental effects on the frequency of heavy alcohol use associated with nonintact family structures persisted after heavy alcohol consumption per occasion was controlled for. This effect did become nonsignificant in the case of adolescents who lived with their fathers and stepmothers, but this finding may be a statistical artifact due to the small number of adolescents living in such households. These findings strongly suggest that the processes associated with nonintact families contribute specifically to routine heavy alcohol use, beyond individual propensity toward heavy drinking. Whereas emotional strain or impaired interpersonal relations may contribute toward heavy drinking, the effects of family structure on the frequency of heavy drinking, net of heavy drinking per occasion, could tentatively be expected to be rooted in structural deficiencies in parental control. Future cross-national studies should examine further such processes underlying the association between family structure and adolescent alcohol use.

On the societal level, the availability of beer and heavy alcohol consumption in adolescent society were both found to contribute to the frequency of individual alcohol consumption, independent of individual propensity toward heavy alcohol use per occasion and individual living arrangements. Furthermore, the adverse effect of living in nonintact families was found to be greater in societies where alcohol availability is greater and heavy alcohol use among adolescents is more widespread. This finding supports the notion that adolescent alcohol use is embedded in a social context that is itreducible to individual circumstances. This context may to a greater or lesser degree pressure individuals toward heavy drinking, and the importance of parental relations can be expected to vary directly with such pressures. Conversely, deficiencies associated with nonintact family structures may become more consequential as the general availability of alcohol and alcohol consumption in adolescent society become greater. Although beer sales were not expected to have a greater predictive value than total alcohol sales or sales of wine or spirits, this finding dovetails nicely with Rossow's (2001) time-series analysis of the association between alcohol sales and homicide rates in Northern, Southern and Eastern Europe between 1950 and 1995. Rossow found that, although the sales figures for different types of alcohol were positively associated with homicide rates in different countries, beer sales were positively and significantly associated with homicide in all three 
regions. The underlying cause of this pattern remains unclear and warrants further research.

Our sample of 15-16 year old students did not enable us to examine the potentially differing patterns of family structure and alcohol consumption among children and adolescents at different ages. Moreover, we were unable to distinguish between widowed, divorced or never-married parents. The adolescents in our sample may thus differ substantially in the length of time they have lived in the current household structure and their level of contact with the absent parent. Finally, our study did not address crossnational differences in informal norms regarding the appropriate age of alcohol consumption, differences in legal drinking age or the enforcement of such rules. Future studies should further explore such societal-level differences and effects on the relationship between adolescent development and heavy alcohol use.

\section{Acknowledgments}

Data for this project were provided by the authors and by A.G. Davidaviciene (Lithuania), P. Miller (Scotland), A. Nociar (Slovak Republic), A. Pavlakis (Cyprus) and E. Stergar (Slovenia). Logistic support was provided by the University at Albany, State University of New York, and research assistance by Benjamin Pearson-Nelson. The final version of this article has been considerably improved by the perceptive comments and constructive suggestions of the editor and two anonymous reviewers.

\section{References}

AdalbJarnardottiR, S., Davidsdottir, S. ANd Runarsdottir, E.M. Ahaettuhegdun Reykviskra Unglinga (The Risk-Taking Behavior of Adolescents), Reykjavik, Iceland: Univ. of Iceland Press, 1997.

ADLAF, E.M AND IVIS, F.J. Structure and relations: The influence of familial factors on adolescent substance use and delinquency. J. Child Adolesc. Subst. Use 5: 1-19, 1996.

AMEY, C.H. AND ALBRECHT, S.L. Race and ethnic differences in adolescent drug use: The impact of family structure and the quantity and quality of parental interaction. J. Drug Issues 28: 283-298, 1998.

Bergmark, K.H. AND Andirsson, T. Development of advanced drinking habits in adolescence: A longitudinal study. Subst. Use Misuse 34: 171-194, 1999.

Bernaurg, J.G. AND Thor and the subculture of delinquency: Factors related to violent behavior and nonviolent delinquency. Youth Soc. 30: 445-460, 1999.

BJARNASON, T. Administration mode bias in a school survey on alcohol, tobacco and illicit drug use. Addiction 90: 555-559, 1995.

BuARnAson, T. Grooming for success? The impact of adolescent society on early intergenerational social mobility. J. Fam. Econ. Issues 21: 319-342, 2000.

Bunnason, T. and Thorionsson, T. Manifest predictors of past suicide attempts in a population of Icelandic adolescents. Suic. Life-Threat. Behav. 24: 350-358, 1994.

Bryk, A.S. anb Raudendusis, S.W. Hierarchical Linear Models: Applications and Data Analysis Methods, Thousand Oaks, CA: Sage, 1992.

Coliman, J.S. The Adolescent Society: The Social Life of the Teenager and Its Impact on Education, New York: Free Press, 1961.

DEAN, A. Culture and community: Drink and soft drugs in Hebridean youth culture. Sociol. Rev. 38: 517-562, 1990,

Dujour, M.C. Risks and benefits of alcohol use over the life span. Alcohol Hlth Res, World 20: 145-151, 1996.
Ely, M., West, P., Sweeting, H. and Richards, M. Teenage family life, life chances, lifestyles and health: A comparison of two contemporary cohorts. Int. J. Law Policy Fam. 14: 1-30, 2000.

ForGaYs, D.K. An evaluation of the relationship between family bonding characteristics and adolescent alcohol use. J. Child Adolesc. Subst. Abuse 7: 1-17, 1998.

Foxcroft, D.R AND Lowe, G. Adolescent drinking behaviour and family socialization factors: A meta-analysis. J. Adolesc. 14: 255-273, 1991.

Glendinning, A., Shucksmirh, J. AND Hendry, L. Family life and smoking in adolescence. Social Sci. Med, 44: 93-101, 1997.

HaNsell, S., White, H.R. and Vali, F.M. Specific alcoholic beverages and physical and mental health among adolescents. J. Stud. Alcohol 60: 209-218, 1999.

Hawkins, J.D., Graitam, J.W., Maguin, E., Abbott, R., Hill, K.G. and Catalano, R.F. Exploring the effects of age of alcohol use initiation and psychosocial risk factors on subsequent alcohol misuse. J. Stud. Alcohol 58: 280-290, 1997.

Hemmingsson, T., Lundaerg, I. and Diderichsen, F. The roles of social class of origin, achieved social class and intergenerational social mobility in explaining social-class inequalities in alcoholism among young men. Social Sci. Med. 49: 1051 1059, 1999.

Hibell, B., Andersson, B., Ahlstrom, S., Balakireva, O., Buarnason, T., Kokkevi, A. And MorGan, M. The 1999 ESPAD (European School Survey Project on Alcohol and Other Drugs) Report: Alcohol and Other Drug Use among Students in 30 European Countries, Stockholm, Sweden: Swedish Council for Information on Alcohol and Other Drigs, 2000 .

JENSEN, G.F, AND BRownFieLD, D. Gender lifestyles, and victimization: Beyond routine activity. Viol. Vict. 1: 85-99, 1986.

KANDEL, D. AND Yamaguchi, K. From beer to crack: Developmental patterns of drug involvement. Amer. J. Publ. Hlth 83: 851-855, 1993.

KOOPMANS, J.R AND BOOMSMA, D.I. Familial resemblances in alcohol use: Genetic or cultural transmission? J. Stud. Alcohol 57: 19.28, 1996.

Lieber, C.S. Hepatic and other medical disorders of alcoholism; From pathogenesis to treatment. J. Stud. Alcohol 59: 9-25, 1998.

MILER, P. Family structure, personality, drinking, smoking and illicit drug use: A study of U.K, teenagers. Drug Alcohol Depend, 45 (1-2): 121$129,1997$.

Millegr, P., Plant, M., Plant, M. and Duffy, J. Alcohol, tobacco, illicit drugs, and sex: An analysis of risky behaviors among young adults. Int. J. Addict. 30: 239-258, 1995.

NTC PubticıTions. World Drink Trends 2000: International Beverage Consumption and Production Trends, Henley-on-Thames, United Kingdom: NTC Publications, 2000.

PACULA, R.L. Adolescent Alcohol and Marijuana Consumption: Is There Really a Gateway Effect? (Working Paper No. 6348), Cambridge, MA: National Bureau of Economic Research, 1998.

Pedersen, W. Marginalitetens reproduksjon (The reproduction of marginality). Tidsskrift for Samfunnsforskning 37: 3-27, 1996.

Pedersen, W. AND Skrondal, A. Alcohol consumption debut: Predictors and consequences. J. Stud. Alcohol 59: 32-42, 1998.

Peece, S. Utilizing culture and behaviour in epidemiological models of alcohol consumption and consequences for Western nations. Alcohol Alcsm 32: 51-64, 1997.

Poulin, C. AND GRallam, L. The association between substance use, unplanned sexual intercourse and other sexual behnviours among adolescent students. Addiction 96; 607-621, 2001.

RoOM, R. AND MAKELX, K. Typologies of the cultural position of drinking. J. Stud. Alcohol 61: 475-483, 2000.

Rossow, I, Alcohol and homicide: A cross-cultural comparison of the relationship in 14 European countries. Addiction 96 (Suppl. No. 1): $\$ 77-\$ 92,2001$.

Rossow, I. AND Wichistrom, L. Parisuicide and use of intoxicants among Norwegian adolescents. Suic. Life-Threat. Belsav. 24: 174-183, 1994. 
SCHMDT, L., RoOM, R. AND COLlaborators. Cross-cultural applicability in intemational classification and research on alcohol dependence. J. Stud. Alcohol 60: 448-462, 1999.

Shucksmith, J., Grendinning, A. ANd Hendry, L. Adolescent drinking behaviour and the role of family life: A Scottish perspective. J. Adolesc. 20: 85-101, 1997.

Sokol-Katz, J., Dunham, R. and Zimmerman, R. Fanily structure versus parental attachment in controlling adolescent deviant behavior: A social control model. Adolescence 32: 199-215, 1997.

Thomas, G., Farrell, M.P. And Barnes, G.M. The effects of single-mother families and nonresident fathers on delinquency and substance abuse in black and white adolescents. J. Marr. Fam. 58: 884-894, 1996 ,

Thorlindson, T., Biarnason, T. and Sigfusdottir, I.D. Social closure, parental and peer networks: A study of adolescent scholastic achicvement and alcohol use. Paper presented at the annual meeting of the American Sociological Association, Anahcim, CA, August 18-21, 2001. Ullman, S.E., Karabatsos, G. and Koss, M.P. Alcohol and sexual aggression in a national sample of college men. Psychol. Women Q. 23: $673-689,1999$.

Wada, K., Price, R.K. and FuKu, S. Reflecting aduit drinking culture: Prevalence of alcolol use and drinking situations anong Japanese junior high school students in Japan. J. Stud. Alcohol 59: 381-386, 1998.

Wallace, J.M., Jr., Forman, T.A., GuThRIL, B.J., BAcIImAn, J.G., O'Malley, P.M., ANI) Jolinsion, L..D. The epidemiology of" alcohol, tobacco and other drug use among black youth. J. Stud. Alcohol 60: $800-809,1999$. 